\title{
Arctic Mixed-Phase Cloud Properties Derived from Surface-Based Sensors
}

\author{
M.D. Shupe and S.Y. Matrosov \\ Cooperative Institute for Research in Environmental Sciences \\ University of Colorado/National Oceanic and Atmospheric Administration \\ Boulder, Colorado \\ T. Uttal
}

National Oceanic and Atmospheric Administration/Environmental Technology Laboratory

Boulder, Colorado

\section{Introduction}

Mixed-phase clouds are an understudied component of global cloudiness and are thus poorly represented in models at all scales, which typically partition cloud phase as a function of temperature. The proper partitioning of cloud phase is particularly important considering the unique radiative properties of liquid droplets and ice particles, the impact of phase on precipitation processes, and the sensitivity of phase transitions to possible climate changes. The limited set of observations and studies concerning Arctic mixed-phase clouds, in particular, leaves substantial ambiguity in our understanding of these clouds and their important mechanisms. Some deficiencies in our understanding of Arctic mixed-phase clouds may be addressed by examining cloud observations from the Surface Heat Budget of the Arctic (SHEBA) Program (Uttal et al. 2002), which occurred from October 1997 through October 1998 in the Beaufort Sea, and from the Atmospheric Radiation Measurement Program's ongoing measurements at the North Slope of Alaska (NSA) site in Barrow, Alaska since spring of 1998. Measurements from these two sites provide a comprehensive view of Arctic cloudiness in all seasons and a particularly wealthy set of mixed-phase cloud observations. Although methods do not currently exist to operationally retrieve all microphysical properties of mixed-phase clouds, some significant and useful micro- and macrophysical properties from these important clouds can be derived from SHEBA and NSA measurements.

\section{Identifying And Characterizing Mixed-Phase Clouds}

Ground-based instruments used in this study are the millimeter cloud radar (MMCR), which provides profiles of radar reflectivity, Doppler velocity, and Doppler spectrum width, the microwave radiometer (MWR), which provides estimates of the column integrated liquid water path (LWP) and water vapor amounts, a depolarization lidar, which provides information on cloud phase (Intrieri et al. 2002), and radiosondes, which provide profiles of temperature and humidity. The instrument suites at both the SHEBA and NSA sites were nearly identical, except that the NSA site lacked lidar depolarization capabilities prior to 2004 . 
Mixed-phase clouds above the SHEBA ice camp and NSA observation site were identified based on the measurements from the above instruments, and are defined as cloud layers containing both liquid and ice water. This definition does not imply that all portions of clouds classified as mixed-phase contain both phases in the same volume. The mixed-phase clouds studied here often consisted of a cloud top liquid layer from which ice particles formed and fell (i.e., Rauber and Tokay 1991), although deep, multilayered scenes were also observed.

In most mixed-phase clouds, since ice particles are typically much larger than liquid droplets, the ice component dominates the radar signal (i.e., Shupe et al. 2004). This dominance is expected to be particularly true for Arctic mixed-phase clouds which often contain only small amounts of liquid $\left(<100 \mathrm{~g} \mathrm{~m}^{-2}\right)$. Empirical relationships for estimating ice water content (IWC) from radar reflectivity $\left(Z_{\mathrm{e}}\right)$ have been explored extensively, following the form IWC $=a \mathrm{Z}_{\mathrm{e}}{ }^{b}$ where the coefficients $a$ and $b$ are fixed or fit to the given situation. By assuming a particle density-size relationship, a characteristic ice particle size can be similarly derived. Radar-only ice retrievals of this type were applied to all identified mixedphase clouds using a fixed $b$ of 0.63 (Matrosov 1999) and an $a$ that varies with season according to statistical results derived from a radar-radiometer retrieval in single-phase Arctic ice clouds (Matrosov 1999). Thus, the empirical relationships employed here are tuned, in a statistical manner, to ice particles observed in the Arctic. Ice cloud microphysical retrievals have 45-m vertical and 1-min temporal resolution.

The MWR, whose channels at 24 and $31 \mathrm{GHz}$ respond only to liquid water, was used to derive the cloud LWP, which is considered a proxy for the mixed-phase cloud liquid microphysical properties since they were not derived directly from other measurements.

\section{Results}

Retrieved mixed-phase cloud properties for both SHEBA and NSA are summarized in Table 1. In the following figures, box-and-whisker plots are utilized which show the median (middle line), $25^{\text {th }}$ and $75^{\text {th }}$ percentiles (edges of box), $5^{\text {th }}$ and $95^{\text {th }}$ percentiles (end of whiskers), and mean (symbol) of the data. For comparison, single-phase cloud properties are included in some figures.

\begin{tabular}{|c|c|c|c|c|}
\hline \multirow{2}{*}{ Parameter } & \multicolumn{2}{|c|}{ SHEBA } & \multicolumn{2}{|c|}{ NSA } \\
\hline & Mean & Range & Mean & Range \\
\hline$A_{c}$ & $41 \%$ & $10-70 \%$ & $46 \%$ & $27-80 \%$ \\
\hline$h_{\text {base }}$ & $0.9 \mathrm{~km}$ & $0-3.5 \mathrm{~km}$ & $0.6 \mathrm{~km}$ & $0-3 \mathrm{~km}$ \\
\hline$\Delta \mathrm{h}_{\text {cld }}$ & $1.9 \mathrm{~km}$ & $0.4-4.4 \mathrm{~km}$ & $1.5 \mathrm{~km}$ & $0.3-4 \mathrm{~km}$ \\
\hline $\mathrm{T}_{\text {cld }}$ & $-14^{\circ} \mathrm{C}$ & $-27--2^{\circ} \mathrm{C}$ & $-14^{\circ} \mathrm{C}$ & $-26--2^{\circ} \mathrm{C}$ \\
\hline $\mathrm{D}_{\text {mean }}$ & $93 \mu \mathrm{m}$ & $27-200 \mu \mathrm{m}$ & -- & -- \\
\hline IWC & $0.027 \mathrm{~g} \mathrm{~m}^{-3}$ & $10^{-4}-0.11 \mathrm{~g} \mathrm{~m}^{-3}$ & -- & -- \\
\hline IWP & $42 \mathrm{~g} \mathrm{~m}^{-2}$ & $0.1-200 \mathrm{~g} \mathrm{~m}^{-2}$ & -- & -- \\
\hline LWP & $61 \mathrm{~g} \mathrm{~m}^{-2}$ & $2.2-180 \mathrm{~g} \mathrm{~m}^{-2}$ & -- & -- \\
\hline
\end{tabular}




\section{Mixed-phase cloud presence and morphology}

Mixed-phase clouds occurred $41 \%$ of the time during the SHEBA annual cycle and $55 \%$ of the time that clouds were present. At the NSA, mixed-phase clouds occur an average of $46 \%$ of the time and $59 \%$ of the time that clouds are present. Figure 1 compares mixed-phase cloud macrophysical properties between the SHEBA and NSA sites. At both sites the monthly mixed-phase cloud fraction $\left(\mathrm{A}_{\mathrm{c}}\right)$ is at a maximum during the spring and fall transition season; however, the SHEBA annual cycle is shifted 1-2 months earlier than the average NSA cycle. The transition seasons also exhibit the lowest monthlyaveraged mixed-phase cloud bases (Figure 1b) because in these seasons low-level stratiform mixedphase clouds with ice crystals extending down to, or near, the surface are the predominant mixed-phase cloud type. Mixed-phase clouds are mildly thinner in May and thicker in mid-summer than in other times of the year. The temperature of mixed-phase clouds $\left(\mathrm{T}_{\text {cld }}\right.$, derived from the ambient temperature at all heights in mixed-phase clouds) varies with season from a monthly-average of -25 to $-20^{\circ} \mathrm{C}$ in winter to a maximum above $-10^{\circ} \mathrm{C}$ in June.

\section{Microphysical Properties}

Mixed-phase cloud microphysical properties are summarized for SHEBA only. The characteristic sizes of ice particles in the mixed-phase clouds observed at SHEBA were, on average, smallest in the winter and largest in the summer (Figure $2 \mathrm{a}$ ), with an annual average $\mathrm{D}_{\text {mean }}$ of $93 \mu \mathrm{m}$. Low values of mixedphase IWC and IWP occurred frequently in all months and, in general, more large values were observed in the summer and fall (Figures $2 \mathrm{~b}$ and $2 \mathrm{c}$ ). The annual mean IWC and IWP were $0.027 \mathrm{~g} \mathrm{~m}^{-3}$ and $42 \mathrm{~g} \mathrm{~m}^{-2}$, respectively. Monthly-mean mixed-phase cloud LWPs, derived from MWR observations in single-layer clouds, were at an annual minimum of less than $50 \mathrm{~g} \mathrm{~m}^{-2}$ in winter/spring and a maximum around $100 \mathrm{~g} \mathrm{~m}^{-2}$ in late fall (Figure 3). The annual mean mixed-phase cloud LWP was $61 \mathrm{~g} \mathrm{~m}^{-2}$. Since detailed information about the liquid droplet sizes and the vertical distribution of liquid water content were not directly inferred from radar measurements for all mixed-phase clouds, statistics on these quantities are not provided.

In general, the mixed-phase clouds observed at SHEBA contained more ice and liquid than single-phase ice or liquid clouds (Figures 2 and 3, single-phase results are from Shupe et al. 2004). Retrieved mixedphase ice particle sizes, IWCs, and IWPs are larger than their single-phase counterparts (derived using the same retrieval method) by, on average, $28 \%, 93 \%$, and $40 \%$, respectively. The liquid water paths observed in mixed-phase clouds tended to be slightly larger, in a monthly- and annual-mean sense, than the LWPs in single-phase clouds (Figure 3a). The annual mean mixed-phase LWP is 30\% larger than the annual mean all-liquid LWP (for the subset of single-layer clouds), with the majority of this difference occurring in the fall and winter months.

Profile statistics were calculated for manually selected cloud layers that were well-developed (not tenuous) and contained only one distinct layer. Cloud profiles were normalized in both cloud depth and parameter value in order to investigate the relative vertical distribution of cloud properties. Statistical analysis was performed on each normalized profile height level. 


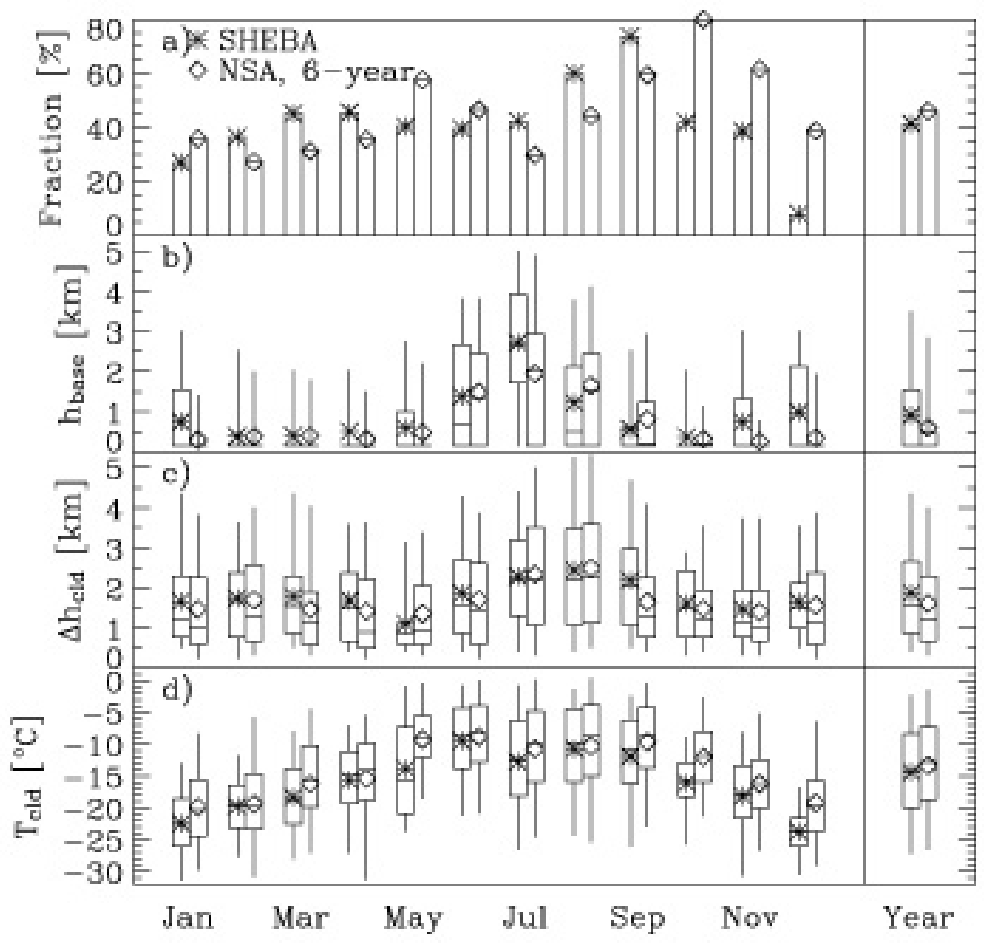

Figure 1. Monthly and annual mixed-phase cloud statistics of (a) occurrence fraction, (b) cloud base height, (c) cloud thickness, and (d) cloud temperature for one year at SHEBA (stars) and six years at NSA (diamonds).

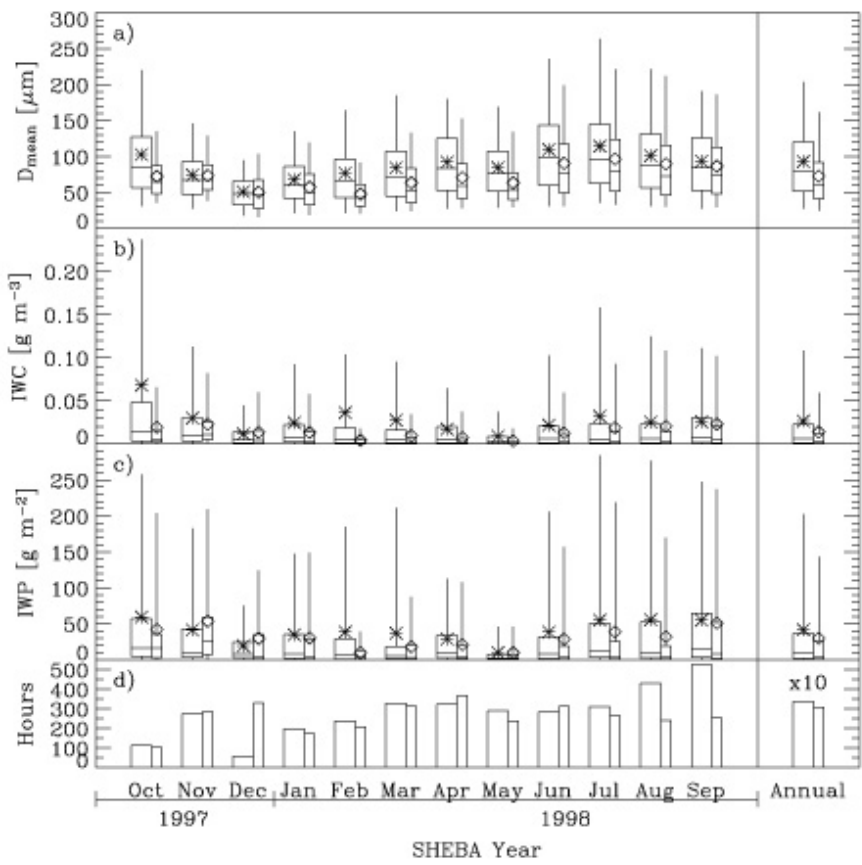

Figure 2. Monthly and annual statistics of cloud (a) $D_{\text {mean }}$, (b) IWC, (c) IWP, and (d) hours of occurrence for mixed-phase (star) and all-ice (diamond) clouds. All-ice cloud results are from Shupe et al. (2004). 


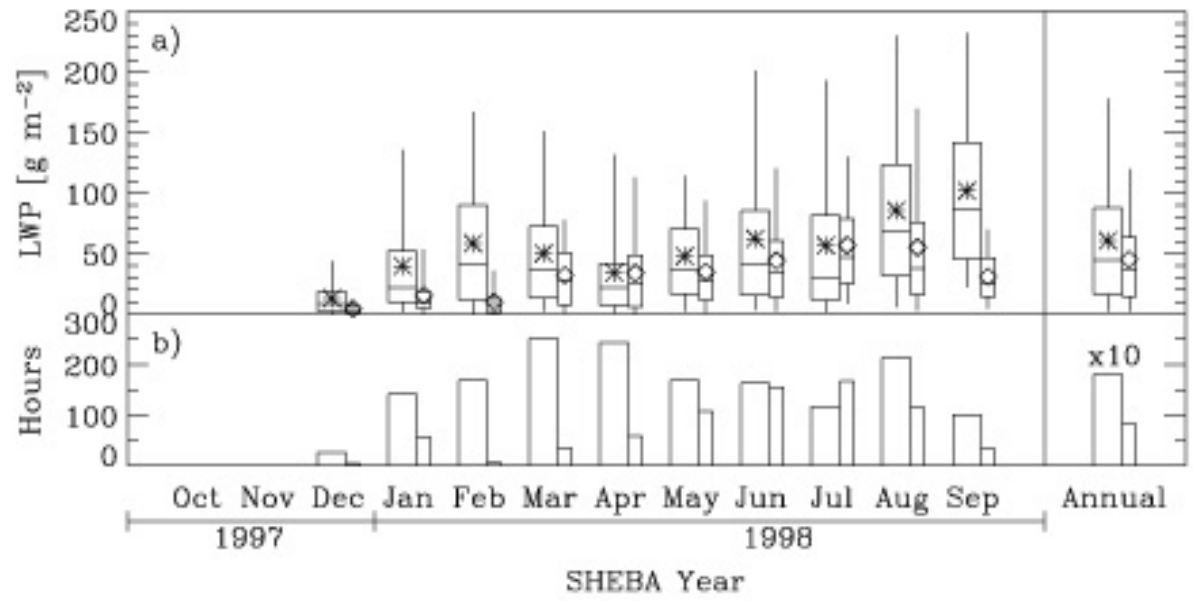

Figure 3. Monthly and annual statistics of cloud (a) LWP and (b) hours of occurrence for single-layer mixed-phase (star) and all-liquid (diamond) clouds. MWR data are not used prior to 7 Dec 1997 due to an irrecoverable calibration error.

There are no apparent annual trends in the vertical distribution of ice within mixed-phase clouds. Figure 4 shows the annual mean normalized profile of mixed-phase cloud IWC (the profile of mixedphase ice $\mathrm{D}_{\text {mean }}$ is similar). A broad maximum in IWC occurs in the upper middle portion of the average mixed-phase cloud. The bulk of the ice mass density was, on average, higher in mixed-phase cloud layers than in all-ice cloud layers (Figure 4). Furthermore, in mixed-phase clouds, the region of largest ice particle sizes and IWCs was much broader than in all-ice clouds.

\section{Phase partitioning with temperature}

The amount of liquid relative to ice in mixed-phase clouds broadly increases with temperature. Figure 5 summarizes the observed relationship between cloud top temperature and the liquid fraction, or the ratio of LWP to total water path (LWP+IWP), in the mixed-phase clouds observed at both SHEBA and the NSA. All cloud scenes included in Figure 5 had tops below $5 \mathrm{~km}$ and positive values of both LWP and IWP. In general, liquid-dominant mixed-phase clouds have cloud top temperatures ranging from -27 to $-2^{\circ} \mathrm{C}$ while ice-dominant clouds have temperatures of -35 to $-10^{\circ} \mathrm{C}$. At any given liquid fraction, the temperature varies over approximately $20-25^{\circ} \mathrm{C}$. The annual average relationship between the liquid fraction and temperature (Figure 5, stars), for both SHEBA and NSA, shows a relatively steep decrease in liquid fraction from -13 to $-24^{\circ} \mathrm{C}$. Since the cloud tops for all clouds discussed in this section are limited to $5 \mathrm{~km}$, the temperature relationships presented are most applicable to lower-level mixed-phase clouds that are often of a stratiform nature. Thicker, multilayered mixed-phase clouds may have somewhat different relationships between the liquid fraction and temperature because of the additional impact of ice crystals falling from above liquid cloud layers (i.e., the seeder-feeder mechanism). 


\section{Discussion}

\section{Mixed- and single-phase cloud differences}

The fact that both the magnitude of ice microphysical properties and their vertical distribution differ between mixed-phase and all-ice clouds observed at SHEBA indicates that there are marked differences in the particle formation and growth mechanisms and the total moisture available for particle growth between these two cloud types. Cirrus clouds (ice only), to a large extent, grow by diffusional growth from water vapor and the growth rates are dependent upon the supply of vapor and the temperature, among other properties, which are both relatively low at the higher altitudes where these clouds are found. The microphysical mechanisms that are active in cirrus clouds can also play a role in mixedphase clouds; however, there are additional conditions and mechanisms that promote more rapid ice growth in mixed-phase clouds. Ice particles can grow relatively faster due to the additional moisture at lower and warmer altitudes. Compared to the mixed-phase cloud temperatures shown in Figure 1d, the all-ice clouds observed at SHEBA were, on average, much colder, with a mean temperature of $-31^{\circ} \mathrm{C}$ and a temperature range $\left(5^{\text {th }}\right.$ to $95^{\text {th }}$ percentiles) of -49 to $-14^{\circ} \mathrm{C}$. In addition, the Bergeron-Findeisen mechanism, under which ice particles grow at the expense of liquid droplets due to an imbalance in saturation vapor pressures, plays a major role in mixed-phase cloud ice formation. The presence of liquid water drops in these clouds can also invoke the ice initiation and growth mechanisms of contact freezing, condensation-freezing, and riming of ice and snow which can cause ice particles to grow more rapidly than through vapor deposition alone.

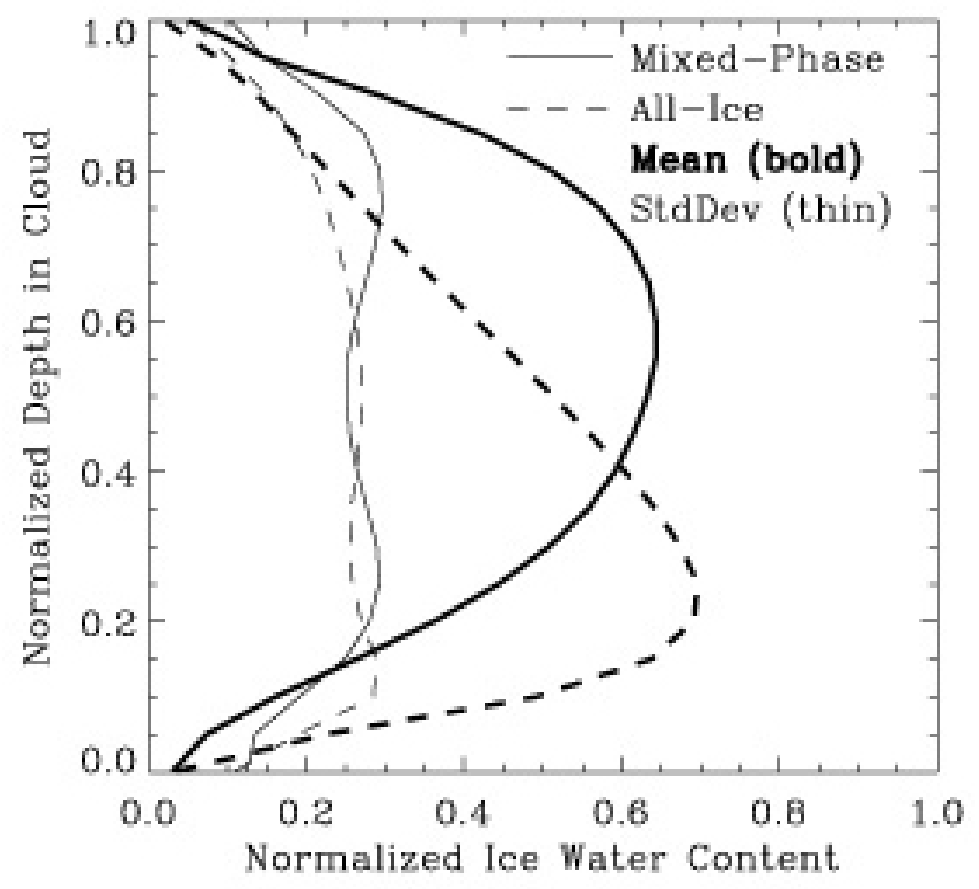

Figure 4. Annual mean, normalized profiles of retrieved IWC (bold) and profiles of the standard deviation (thin) for mixed-phase (solid) and all-ice (dashed) clouds. The all-ice cloud results are from Shupe et al. (2004). 


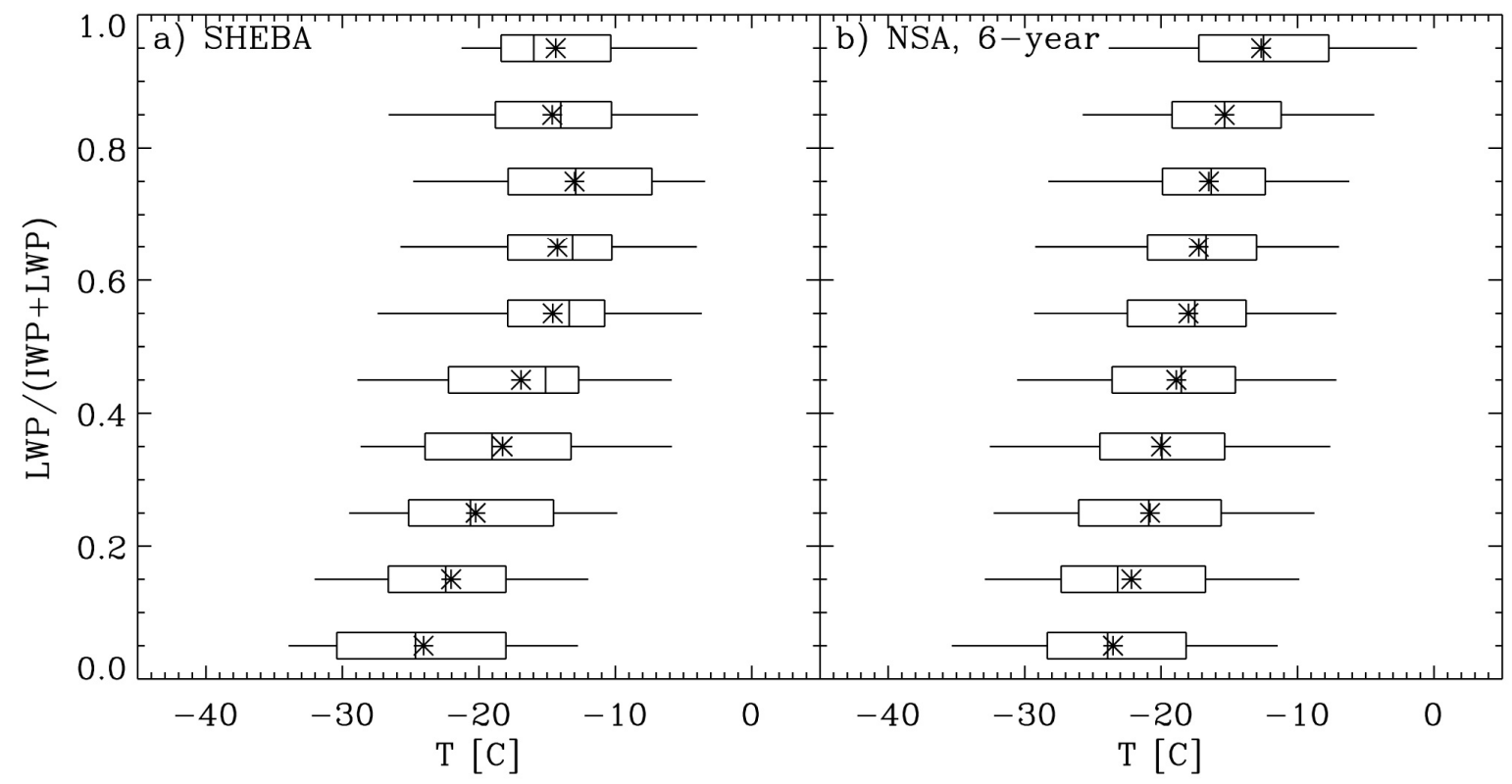

Figure 5. Box-and-whisker plots showing the liquid fraction [LWP/(LWP_IWP)] versus cloud top temperature for mixed-phase clouds at (a) SHEBA for one year and (b) NSA for six years.

The vertical profiles of ice microphysical properties (Figure 4) also suggest that the growth of ice in mixed-phase clouds is largely tied to the presence of liquid water. For all-ice clouds, the ice particles and ice water content grow throughout the top $75 \%$ of the cloud layer, while sublimation occurs only in a thin layer near the cloud base. In contrast, mixed-phase cloud ice growth occurs in the top $1 / 3$ of the average cloud layer with a broad maximum in the upper-middle portion of the cloud layer. This profile shape can be attributed to the presence of liquid water near the tops of these clouds.

These data reveal that the total LWP of mixed-phase clouds observed at SHEBA was larger than the LWP observed in all-liquid clouds. However, the data also indicate that this disparity may have been due to differences in the liquid cloud layer thickness (and thus vertical motions) instead of differing droplet formation/growth mechanisms. For the subsets of mixed-phase and all-liquid clouds that were single-layer and below $5 \mathrm{~km}$ at SHEBA, the annual mean LWPs were 43 and $23 \mathrm{~g} \mathrm{~m}^{-2}$, respectively. Using lidar measurements to derive the base of the liquid cloud layers (which are typically somewhat above the base of the cloud ice) and the radar to derive cloud top heights (e.g., Intrieri et al. 2002), the mean liquid cloud layer thicknesses for stratiform mixed-phase and all-liquid clouds were 620 and $350 \mathrm{~m}$, respectively. Although the liquid water content was not directly retrieved from these clouds, these statistics together suggest that the mean liquid water contents for this subset of mixed-phase and all-liquid clouds were approximately the same: 0.069 and $0.066 \mathrm{~g} \mathrm{~m}^{-3}$, respectively. Therefore, although the mixed-phase clouds contained, on average, more liquid water than the all-liquid clouds, both of these cloud types contained approximately the same amount of liquid water per vertical extent. 


\section{Temperature and radiation considerations}

Temperature plays a key role in determining mixed-phase cloud occurrence and composition. The fact that mixed-phase clouds tend to occur more frequently in the spring and fall transition seasons (Figure 1a) suggests that the temperature range during these seasons is most conducive to the coexistence of multiple cloud phases. Radiation may also play a role, since the SW radiative warming of the cloud top decreases at low sun angles, allowing for a relatively larger LW radiative cooling to drive the updrafts that are necessary to form and sustain the liquid water in these clouds (i.e., Rauber and Tokay 1991).

The relationship between temperature and liquid fraction in mixed-phase clouds is particularly important for climate models. The data presented in Figure 5 suggests a general trend towards higher liquid fractions at warmer temperatures with a substantial amount of variation in temperature at any given liquid fraction. The increase of the liquid fraction with temperature is predominantly due to increases in LWP with temperature (i.e., Clausius-Clapeyron) and less due to decreases in IWP with temperature. On average, the retrieved mixed-phase cloud ice properties at SHEBA changed very little with cloud temperature over the range of -40 to $-10^{\circ} \mathrm{C}$ (not shown).

The data in Figure 5 are similar to previous observations of phase partitioning with temperature, yet the spread of available observations is large. Differences in the temperature-phase relationship may be expected as the conditions that impact this relationship differ regionally, and likely seasonally, based on sources of moisture, ice forming nucleus type and concentration, vertical motions, and the net cooling rate (e.g., Pinto 1998). These data support model parameterizations that are able to form cloud liquid at temperatures down to $-35^{\circ} \mathrm{C}$. Finally, these observations show a range of about $25^{\circ} \mathrm{C}$ at any given liquid fraction which complicates the ability to accurately parameterize the partitioning of cloud phases based on temperature alone. Cloud phase parameterizations based on additional parameters will likely be necessary to capture the natural variability of Arctic cloud phase distributions.

\section{Conclusions}

This paper provides important information on mixed-phase cloud macro- and microphysical properties at both SHEBA and the NSA. Cloud height, thickness, and temperature are derived directly from radar measurements and interpolated temperature soundings. Ice microphysical properties are derived from radar reflectivity measurements under the assumption that the large ice crystals dominate the radar signal from these clouds. Microwave radiometer retrievals of LWP are used to characterize the total liquid water present in mixed-phase clouds.

Major conclusions concerning the macro- and microphysical properties of Arctic mixed-phase clouds include:

- Mixed-phase clouds occur 41-46\% of the time in the Arctic, and 55-59\% of the time that clouds are observed. The majority of mixed-phase clouds occur in the spring and fall transition seasons.

- $\quad$ Mixed-phase clouds occur at temperatures ranging from -35 to $-2^{\circ} \mathrm{C}$. These clouds are most often $\sim 1-3 \mathrm{~km}$ thick with a cloud base near the surface. 
- Annual mean mixed-phase microphysical properties derived from SHEBA observations are: $\mathrm{D}_{\text {mean }}=93 \mu \mathrm{m}, \mathrm{IWC}=0.027 \mathrm{~g} \mathrm{~m}^{-3}, \mathrm{IWP}=42 \mathrm{~g} \mathrm{~m}^{-2}$, and LWP $=61 \mathrm{~g} \mathrm{~m}^{-2}$. These are all larger than the equivalent single-phase cloud properties from SHEBA presented by Shupe et al. (2004).

- $\quad$ IWC and $\mathrm{D}_{\text {mean }}$ reach a broad maximum in the upper middle portion of the average single-layer mixed-phase cloud at SHEBA, somewhat higher within the cloud than in single-phase ice clouds. This profile shape, and the difference from single-phase ice clouds, is likely associated with the liquid water source near the cloud top.

- The liquid fraction, or the ratio of liquid water to total condensed water, increases with temperature. The annual average relationship shows a transition from full glaciation at $-24^{\circ} \mathrm{C}$ to complete liquid water at $-13^{\circ} \mathrm{C}$, although at any given liquid fraction there is a $25^{\circ} \mathrm{C}$ range of observed temperatures.

Considerable work and new measurements are needed to produce a more complete characterization of Arctic mixed-phase cloud properties. Retrieval methods can be developed, improved, and better validated. Additional study is also necessary to determine the spatial variability of Arctic mixed-phase cloudiness, and to specifically investigate why more cloud ice and liquid occur in mixed-phase clouds than in single-phase clouds. Finally, a broader analysis involving more parameters will be necessary to further constrain the cloud phase-temperature relationship in order to improve model phase partitioning parameterizations.

\section{Contact}

Matthew Shupe, matthew.shupe@noaa.gov, (303) 497-6471

\section{Acknowledgment}

This research was supported by the NSF SHEBA (OPP-9701730), the NASA FIRE-ACE (L64205D), the NASA EOS Validation (S-97895-F), and NOAA SEARCH programs. In addition, this research was supported by the Office of Biological and Environmental Research of the U.S. Department of Energy as part of the Atmospheric Radiation Measurement Program.

\section{References}

Intrieri, JM, MD Shupe, T Uttal, and BJ McCarty. 2002. "Arctic cloud statistics from lidar and radar at SHEBA.” Journal of Geophysical Research 107:8030.

Matrosov, SY. 1999. "Retrievals of vertical profiles of ice cloud microphysics from radar and IR measurements using tuned regressions between reflectivity and cloud parameters." Journal of Geophysical Research 104:16,741-16,753.

Pinto, JO. 1998. "Autumnal mixed-phase cloudy boundary layers in the Arctic." Journal of Atmospheric Science 55:2016-2038. 
Rauber, RM, and A Tokay. 1991. "An explanation for the existence of supercooled water at the top of cold clouds." Journal of Atmospheric Science 48:1005-1023.

Shupe, MD, T Uttal, and SY Matrosov. 2004. "Arctic cloud microphysics derived from surface-based remote-sensors at SHEBA." Journal of Applied Meteorology, submitted.

Uttal T, JA Curry, MG McPhee, DK Perovich, RE Moritz, JA Maslanik, PS Guest, HL Stern, JA Moore, R Turenne, A Heiberg, MC Serreze, DP Wylie, OG Persson, CA Paulson, C Halle, JH Morison, PA Wheeler, A Makshtas, H Welch, MD Shupe, JM Intrieri, K Stamnes, RW Lindsey, R Pinkel, WS Pegau, TP Stanton, TC Grenfeld. 2002. "Surface Heat Budget of the Arctic Ocean." Bulletin of the American Meteorological Society 83:255-275. 